\title{
Hepatitis C: A South African literature review and results from a burden of disease study among a cohort of drug-using men who have sex with men in Cape Town, South Africa
}

\author{
N P Semugoma, ${ }^{1}$ MD; K Rebe,${ }^{1,2,3}$ MB ChB, FCP (SA); M W Sonderup, ${ }^{4}$ MB ChB, FCP (SA); M Kamkeumah, ${ }^{5}$ MPH; G de Swardt ${ }^{2}$ BA \\ H Struthers, ${ }^{2,3} \mathrm{PhD}$; H Eksen, ${ }^{6} \mathrm{BA}$; J McIntyre, ${ }^{2,5} \mathrm{MB} \mathrm{ChB}, \mathrm{FRCOG}$ \\ ${ }^{1}$ Anova Health Institute, Cape Town, South Africa \\ ${ }^{2}$ Anova Health Institute, Johannesburg, South Africa \\ ${ }^{3}$ Department of Medicine, Faculty of Health Sciences, University of Cape Town, South Africa \\ ${ }^{4}$ Division of Hepatology, Department of Medicine, Faculty of Health Sciences, University of Cape Town, South Africa \\ ${ }^{5}$ School of Public Health, Faculty of Health Sciences, University of Cape Town, South Africa \\ ${ }^{6}$ Mainline, Amsterdam, the Netherlands
}

Corresponding author: KRebe (rebe@anovahealth.co.za)

Background. Hepatitis C virus (HCV) is a chronic infection of increasing importance, especially among people living with HIV/AIDS. Co-infection with HIV can accelerate progression of HCV liver disease to cirrhosis and end-stage liver failure and elevate the risk of hepatocellular carcinoma. Globally, men who have sex with men (MSM) and people who inject drugs are at increased risk of HCV infection compared with the general population. Few studies on HCV in these key populations have been done in South Africa (SA).

Objective. To describe the disease burden of HCV in drug-using MSM who attend harm-reduction services at the Anova Health Institute's Health4Men clinic in Cape Town, SA.

Methods. In 2012 - 2014, attendees of an MSM-focused harm-reduction programme were invited to participate in our study. After informed consent, participants completed a brief demographic questionnaire and underwent phlebotomy for anti-HCV antibody, hepatitis B virus (HBV) surface antigen and surface antibody testing. Participants received counselling and education with regard to their results. HIV status was extracted from the case notes of participants who had previously been tested at the study site. Data were analysed using standard statistical techniques.

Results. Forty-one MSM were enrolled - 11 (27.0\%) tested anti-HCV antibody-positive, indicating prior exposure to HCV or chronic infection; 10/11 (91.0\%) were positive for HBV surface antibodies, suggesting previous HBV exposure or vaccination; and 1 (2.0\%) screened positive for HBV. Of the HCV-seropositive individuals, HIV status was known in 8/11; 3/8 (37.5\%) were HIV-positive.

Conclusion. We demonstrated a high burden of HCV exposure or infection among a small urban cohort of MSM who inject drugs. We recommend active screening of MSM (especially those who report drug use) for HCV, and the development of referral networks for access to treatment.

S Afr Med J 2017;107(12):1116-1120. DOI:10.7196/SAMJ.2017.v107i12.12623

Globally, the hepatitis $\mathrm{C}$ virus (HCV) is an infection of increasing significance. ${ }^{[1]}$ First clinically described as a cause of 'non-A, non-B' post-transfusion hepatitis, it was cloned, named, and characterised in $1989 .{ }^{[2]}$ An estimated 170 million people are chronically infected with HCV, predominantly in Africa, Asia, Eastern Europe and South America. ${ }^{[3]}$

$\mathrm{HCV}$ is a positive-sense RNA virus of the Flaviviridae family, residing in cell cytoplasm. ${ }^{[2]}$ It infects mostly hepatocytes and can be cleared spontaneously by effective host immune responses in 18 - 34\% of cases. ${ }^{[2]}$ The remainder progress to chronic infection, as the virus evades clearance owing to a variety of immune escape mechanisms. Re-infection can occur spontaneously or after treatment-associated viral clearance. ${ }^{[1,2]}$

\section{Clinical presentation and diagnosis}

Clinically, HCV is initially asymptomatic. ${ }^{[2]}$ In $20-40 \%$ of cases, chronic infection leads to fibrosis, cirrhosis and end-stage liver failure over 20 - 30 years. ${ }^{[2]}$ Established cirrhosis has a $1-5 \%$ annual risk of hepatocellular carcinoma (HCC) and a $3-6 \%$ risk of hepatic decompensation. ${ }^{[2]}$ Following hepatic decompensation, the risk of death over the ensuing year is $15-20 \%{ }^{[2]}$ Accelerated progression is associated with co-infection with hepatitis B virus (HBV) and/or $\mathrm{HIV}$, alcohol use, obesity and iron-overload state. ${ }^{[2,4,5]}$

Serological tests confirm HCV exposure and are useful for screening. First-generation HCV IgG ELISA tests were nonspecific, and most current peer-reviewed publications exclude these studies. Second-, third- and fourth-generation serological tests are acceptable, although there are notable accuracy issues in HIV co-infection and among black Africans. ${ }^{[6-8]}$

Region-specific HCV screening algorithms have been developed to try to reliably exclude false positives $(\leq 25 \%)$ and to identify resolved, possible acute or possible chronic infection to guide subsequent management. . $^{[7-9]}$

The reverse transcriptase polymerase chain reaction (RT-PCR) is the gold standard test for HCV, signifying active infection, and allows for qualitative or quantitative testing. ${ }^{[2]}$ Further nucleic acid tests confirm genotype.

Acute HCV infection in HIV-positive patients leads to a long, possibly irregular latency period before seroconversion. Therefore, Kaplan-Lewis and Fierer ${ }^{[10]}$ argue for regular liver function test 
screening as a more sensitive indicator of incident infection in HIVpositive patients.

HCV infection is curable and the new oral regimens with directacting antiviral (DAA) agents have revolutionised management. Successful treatment halts or slows the progression to chronicity, fibrosis, cirrhosis, end-stage renal failure and HCC. ${ }^{[2,5]}$

\section{HCV and HIV}

$\mathrm{HIV}$ and $\mathrm{HCV}$ co-infection occurs, in part due to shared transmission routes and behavioural risk factors. ${ }^{[2,4]}$

Evidence for HCV changing the course of HIV disease is equivocal, ${ }^{[4,10]}$ but a considerable body of evidence shows that HIV changes the course of HCV progression. HIV-positive patients have higher HCV viral loads with lower clearance rates, ${ }^{[2,4]}$ seroconversion (becoming HCV IgG-seropositive) occurs later or might not occur, ${ }^{[8]}$ the progression to liver fibrosis, cirrhosis and end-stage liver disease is faster, and HCC incidence rates are higher. ${ }^{[2,4,5]}$

Some HIV-positive patients demonstrate ultra-rapid progression of hepatic fibrosis to cirrhosis and end-stage liver disease within 3 - 8 years of acute HCV infection. ${ }^{[10]}$ The rapid progression seems to be related to acute $\mathrm{HCV}$ with significant immune suppression, but can occur at higher CD4+ counts. ${ }^{[4]}$

\section{Transmission and epidemiology}

Before 1992, blood transfusion was an important risk factor for HCV infection. Nosocomial infection is a problem for patients receiving haemodialysis. ${ }^{[1]}$ Unsafe injecting practices, tattooing, scarification, and medical parenteral drug administration are additional risk factors. ${ }^{[2,4]}$ The predominant route of transmission is unknown in parts of central Africa, e.g. Cameroon, where HCV is endemic, with rates of $\geq 6 \%$ in the general population. ${ }^{[6]}$

The injection of drugs is currently one of the most important routes of transmission owing to unsafe injecting practices, such as sharing of needles, syringes and drug-use paraphernalia. HCV seroprevalence rates among people who inject drugs (PWID) can be $\leq 90 \%{ }^{[4]}$

There is not much evidence for the sexual transmission of HCV during monogamous heterosexual sex. ${ }^{[5]}$ Sexually transmitted infections (STIs), HIV and multiple sexual partners increase the risk of HCV infection. ${ }^{[12]}$ The sexual behaviour of men who have sex with men (MSM) is an important risk factor for transmission of HIV and $\mathrm{HCV}^{[12]}$

Epidemics of HCV in HIV-positive MSM have been documented since the 1990s in Europe, North America, Asia, and Australia. ${ }^{[1,13]}$ There are also reports of high rates of HCV in HIV-positive MSM in KwaZulu-Natal and Cape Town, South Africa (SA). ${ }^{[14,15]}$

People living with HIV/AIDS (PLWHA) have higher odds of being HCV-seropositive than those without HIV, with a pooled odds ratio (OR) of 5.8 (95\% confidence interval (CI) 4.5 - 7.4) in a recent (2016) World Health Organization (WHO)-commissioned global HIV/HCV co-infection review and meta-analysis authored by Platt $e t$ al. ${ }^{[16]}$ In the review, median co-infection prevalence rates (HIV/HCV) differed by population, being $2.4 \%$ (interquartile range (IQR) 0.8 - 5.8) for general populations, 6.4\% (IQR 3.2 - 10.0) for MSM and 82.4\% (IQR 55.2 - 88.5) among PWID.

\section{Africa and South Africa}

In Africa, HCV seroprevalence varies regionally. In Egypt, adult seroprevalence among the general population is very high $(14.70 \%$; $95 \%$ CI 10.30 - 18.00). There are high rates in central Africa (6.76\%; $95 \%$ CI $5.98-7.55)$, and lower rates in west Africa (4.34\%; $95 \%$ CI $3.99-4.70)$, with the lowest rates in east and southern Africa $(0.91 \% ; 95 \%$ CI $0.80-1.20){ }^{[6]}$
SA is thought to have low rates of HCV in the general population, but with regional and population differences. Table 1 summarises reported HCV seroprevalence rates among differing cohorts. These generally confirm a low seroprevalence in many provinces - Gauteng, Limpopo, and the Western Cape, with the notable exception of KwaZulu-Natal.

Few studies have been conducted among MSM PWID in SA. Our study is an exploratory project to enlarge the information base about MSM who use drugs and to highlight the need for further research.

\section{Study design}

The Ivan Toms Centre for Men's Health (ITCMH) is operated by the Anova Health Institute with funding from the US President's Emergency Plan for AIDS Relief/US Agency for International Development (PEPFAR/USAID) Global Fund and the Elton John AIDS Foundation, in collaboration with the National Department of Health. The ITCMH offers MSM primary healthcare services related to sexual health, including STI diagnosis and treatment, HIV testing, antiretroviral treatment, post-exposure prophylaxis (PEP) and pre-exposure prophylaxis (PrEP). The ITCMH has been providing services to key populations since 2010 and has extensive experience in working with them. In 2012, an MSM-targeted drug harm-reduction programme, including needle exchange, but lacking opioid-substitution therapy, was established, funded by the AIDS Fonds, Mainline, the Netherlands. This service, the first of its kind in SA, was delivered at the ITCMH, which is a centre of excellence and forms part of Anova's Health4Men Initiative. The harm-reduction programme was in operation for about 18 months, when it was halted owing to a lack of sustainable funding. All programmatic knowledge and materials were subsequently handed over to the TB HIV Care Association, which received funding to continue services based on the Anova model.

Harm-reduction programme attendees were approached and screened for enrolment in this study. Inclusion criteria included: adult male, reporting MSM, existing client of the harm-reduction programme, not known to be HCV-positive, able to understand study procedures, and provision of informed consent. Exclusion criteria included: women, age $<18$ years, exclusive heterosexuality, intoxication during clinic visit, and unable or unwilling to give informed consent. People who met the inclusion criteria provided written informed consent to participate. Research activities were approved and overseen by the Human Sciences Ethics Committee, University of Cape Town.

Respondents who consented completed a short researcheradministered questionnaire, including questions about participants' demographics, health (e.g. prior STIs, viral hepatitis screening, vaccination and treatment, HIV and health access), sexual behaviour and drug use behaviour. Venous blood was drawn for HCV IgG (and HBV surface antigen and antibody) tests. Participants were requested to return for their results 2 weeks after study enrolment. They were provided counselling regarding their results and were linked to care if they screened positive for viral hepatitis. HBV-susceptible participants were vaccinated. Study participants were reimbursed ZAR20 ( USD2) at each visit for travel costs.

HCV screening was performed with the Roche Cobas 6000 analyser: Module e601 (Roche, Switzerland). Because of funding constraints, liver function tests, HIV testing and HCV viral load and genotype testing were not included in the study; however, HIV, HCV and genotype results could be obtained for some participants.

Basic descriptive statistics were used to summarise cohort characteristics using Stata version 12.0 (StataCorp., USA). 


\begin{tabular}{|c|c|c|c|c|c|}
\hline Study reference & Study period & Province/region & Population & $n$ & Serology rates, \% \\
\hline Gededzha et al..$^{[17]}$ & $2004-2006$ & Gauteng & HIV-positive & 653 & 1.2 \\
\hline Gogela et al. ${ }^{[18]}$ & Not stated & Western Cape & HIV-positive & 313 & 3.2 \\
\hline Firnhaber et al..$^{[19]}$ & Not stated & Gauteng & HIV-positive & 502 & 0.0 \\
\hline Hoffmann et al..$^{[20]}$ & 2002 & Gauteng & $\begin{array}{l}\text { HIV-positive, } \\
\text { antenatal clinic }\end{array}$ & 994 & 0.1 \\
\hline Barth et al..$^{[21]}$ & Sept. - Nov. 2008 & Limpopo & HIV-positive, clinic & 258 & 0.8 \\
\hline Amin et al..$^{[12]}$ & $\begin{array}{l}1995 \text { - } 1996, \\
52 \text { weeks follow-up }\end{array}$ & Multisite in SA & $\begin{array}{l}\text { HIV-positive, } \\
\text { SA participants were } \\
\text { mainly white }\end{array}$ & - & 1.9 \\
\hline Lodenyo et al. ${ }^{[22]}$ & 1999 & Gauteng & HIV-positive & 100 & 1.0 \\
\hline \multirow[t]{3}{*}{ Parboosing et al. ${ }^{[15]}$} & Jan. 2004 - June 2005 & KwaZulu-Natal & HTC specimens & 1937 & 6.4 \\
\hline & & & $\begin{array}{l}\text { Only HIV-positive } \\
\text { specimens }\end{array}$ & - & 13.4 \\
\hline & & & $\begin{array}{l}\text { Only HIV-negative } \\
\text { specimens }\end{array}$ & - & 1.7 \\
\hline \multirow[t]{4}{*}{ Tathiah et al. ${ }^{[14]}$} & $2002-2010$ & KwaZulu-Natal & $\begin{array}{l}\text { Routine tests submitted } \\
\text { to tertiary laboratory } \\
\text { (with differing } \\
\text { denominators) }\end{array}$ & - & - \\
\hline & & & All anti-HCV Ig tests & 79216 & 4.1 \\
\hline & & & $\begin{array}{l}\text { Of those tested for HIV: } \\
\text { HIV-positive }\end{array}$ & 3425 & 5.1 \\
\hline & & & $\begin{array}{l}\text { Of those tested for HIV: } \\
\text { HIV-negative }\end{array}$ & 14696 & 1.8 \\
\hline
\end{tabular}

\section{Ethical approval}

The study received ethical approval from the Human Sciences Research Ethics Committee, University of Cape Town (ref. no. HSREC 494/2014). Study activities complied with the Declaration of Helsinki.

\section{Results}

Forty-two MSM were enrolled. One was withdrawn from analysis owing to missing data. Baseline characteristics are summarised in Table 2. The median age was 26 (IQR 30 - 40) years. Ethnically, most were mixed race $(n=23 ; 56 \%)$ or white $(n=16 ; 39 \%) ; 39(95 \%)$ participants identified as male, and $2(5 \%)$ as transgender women. Participants' self-reported sexual orientation was homosexual ( $n=18$; $44 \%)$, bisexual $(n=16 ; 39 \%)$, and heterosexual $(n=5 ; 12 \%)$, while 2 (5\%) did not disclose their sexual orientation.

The median duration of drug use was 11 (IQR 9 - 15) years. Drugs used included heroin and crystal methamphetamine, with 33 (80\%) and 37 (90\%), respectively, reporting use in the past 3 months; 28 (68\%) stated that heroin was their drug of choice and 27 (67\%) that crystal methamphetamine was their main drug. Thirty-three $(80 \%)$ reported injecting drugs in the past 3 months, while $36(88 \%)$ reported having ever injected drugs. Twenty-two (54\%) disposed of used needles in regular garbage bins, 2 (5\%) indicated that they kept needles for re-use, and 11 (27\%) reported returning needles to the harm-reduction programme site, while 29 (71\%) admitted having ever shared used needles, syringes or drug preparation equipment.

The median number of sexual partners reported in past 3 months was 2 (IQR 1 - 6), 11 (27\%) reported not using a condom in the past 3 months, and only $6(15 \%)$ reported consistent condom use.
Eleven of the 41 (27\%) participants screened positive for anti-HCV IgG.

HIV serological results were available for 30 (73\%) of the enrolled participants; of these, 12/30 (40\%) were HIV-seropositive. HIV status was known in $8 / 11$ participants with positive HCV IgG results, and 3/8 (37.5\%) were HIV-positive.

Nucleic acid test results were subsequently available for 6 patients with positive HCV IgG, while 1 was PCR-negative (infection presumed cleared). For the other 5 participants, genotypes included: 3 genotype $1 \mathrm{~b}, 1$ genotype $1 \mathrm{a}$, and 1 genotype $4 \mathrm{~b}$.

Ten of 11 anti-HCV seropositive cases (91\%) were also positive for HBV surface antigen, implying either exposure to HBV or anti-HBV vaccination.

One participant screened positive for $\mathrm{HBV}$ infection (positive HBV surface antigen), but none screened positive for both HCV and HBV. These results are summarised in Fig. 1.

\section{Discussion}

To our knowledge, this is the first description of HCV prevalence and risk factors among SA MSM who use drugs. The observed seroprevalence of $27 \%$, compared with reports from sub-Saharan Africa, is high. Comparable rates in PWID populations include $16.4 \%$ in Malindi, Kenya, $22.2 \%$ in Nairobi, Kenya, $7.7 \%$ in Lagos, Nigeria, 23.3\% in Dakar, Senegal and 27.7\% in Temeke, Dar-esSalaam, Tanzania. ${ }^{[23-27]}$ The observed seroprevalence is lower than the reported range of $22-94 \%$ in the Maghreb region of north Africa. ${ }^{[28]}$

These results imply a considerable HCV disease burden in SA among drug-using MSM. Given that screening in the general 
Table 2. Summary of characteristics of enrolled participants $(N=41)$

\begin{tabular}{|c|c|c|}
\hline $\begin{array}{l}\text { Variable, participant } \\
\text { demographics }\end{array}$ & $n(\%)$ & Median (IQR) \\
\hline Age at enrolment, years & - & $26(30-40)$ \\
\hline \multicolumn{3}{|l|}{ Race } \\
\hline Mixed & $23(56)$ & - \\
\hline White & $16(39)$ & - \\
\hline Black African & $1(2)$ & - \\
\hline Asian & $1(2)$ & - \\
\hline \multicolumn{3}{|l|}{ Sexual orientation } \\
\hline Bisexual & $16(39)$ & - \\
\hline Gay & $18(44)$ & - \\
\hline Straight & $5(12)$ & - \\
\hline \multicolumn{3}{|l|}{ Reported drug use } \\
\hline Duration, years & - & $11(9-15)$ \\
\hline \multicolumn{3}{|l|}{ Drugs used in the past 3 months } \\
\hline Heroin & $33(80)$ & - \\
\hline Crystal methamphetamine & $37(90)$ & - \\
\hline Other & $19(46)$ & - \\
\hline \multicolumn{3}{|l|}{ Main (preferred) drugs used } \\
\hline Heroin & $28(68)$ & - \\
\hline Crystal methamphetamine & $27(66)$ & - \\
\hline Other & $12(32)$ & - \\
\hline \multicolumn{3}{|l|}{ Place of use } \\
\hline Home & $22(54)$ & - \\
\hline Friend's home & $16(39)$ & - \\
\hline Party & $8(20)$ & - \\
\hline Street & $21(51)$ & - \\
\hline Bar/club/shebeen & $7(17)$ & - \\
\hline Sex party & $6(15)$ & - \\
\hline $\begin{array}{l}\text { Other (graveyard, work, public } \\
\text { toilet, vehicle, unspecified) }\end{array}$ & $8(20)$ & - \\
\hline \multicolumn{3}{|l|}{ Drug-injecting behaviour } \\
\hline Ever injected & $36(88)$ & - \\
\hline In the past 3 months & $33(80)$ & - \\
\hline Non-intravenous & $32(78)$ & - \\
\hline Intravenous and non-intravenous & $27(66)$ & - \\
\hline Ever shared equipment or needles & $29(71)$ & - \\
\hline \multicolumn{3}{|c|}{$\begin{array}{l}\text { Needle and drug-equipment } \\
\text { disposal }\end{array}$} \\
\hline Rubbish bin & $22(54)$ & - \\
\hline Kept for re-use & $2(5)$ & - \\
\hline Returned to clinic & $11(27)$ & - \\
\hline Not available & $6(14)$ & - \\
\hline \multicolumn{3}{|l|}{ Sexual behaviour } \\
\hline $\begin{array}{l}\text { Sexual partners in the past } 3 \\
\text { months, } n\end{array}$ & - & $2(1-6)$ \\
\hline \multicolumn{3}{|l|}{ Condom use in the past 3 months } \\
\hline Never & $11(27)$ & - \\
\hline Some of the time & $6(15)$ & - \\
\hline Most of time & $13(32)$ & - \\
\hline All of the time & $6(15)$ & - \\
\hline Not reported/applicable & $5(12)$ & - \\
\hline
\end{tabular}

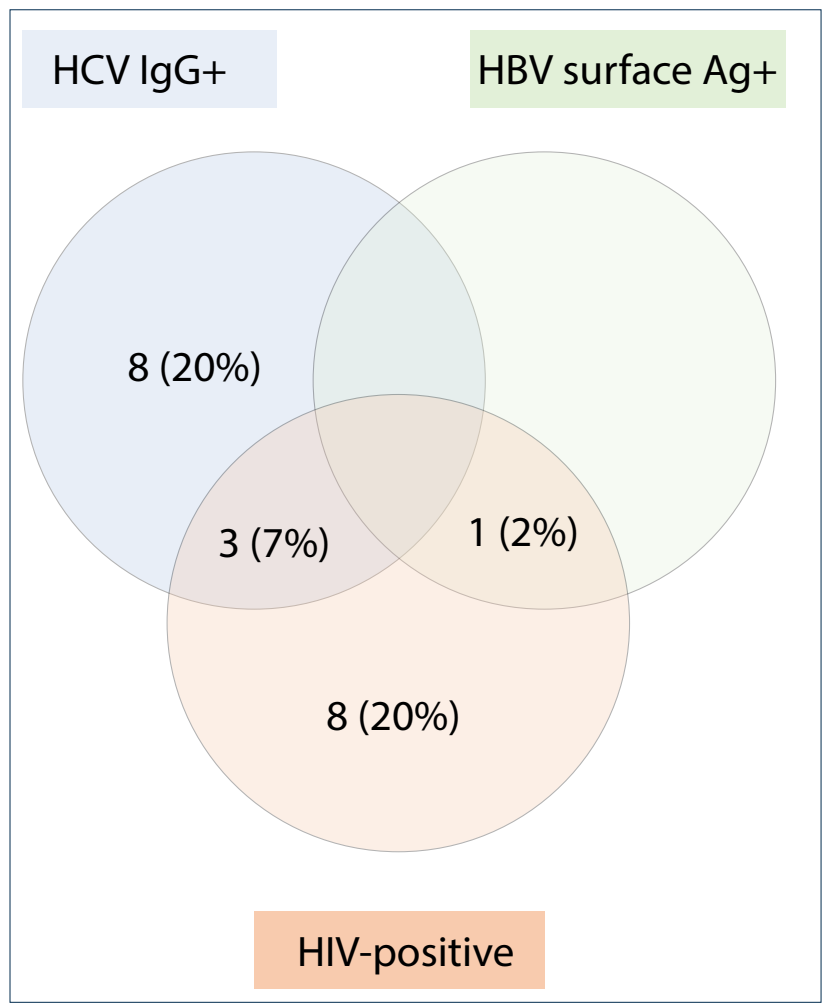

Fig. 1. Viral serostatus: number and percentage of a total of 41 participants. ( $H C V=$ hepatitis $C$ virus; $H B V$ surface $A g=$ hepatitis $B$ virus surface antigen.$)$

population and HIV-positive populations yields a seroprevalence rate of $0.3-1.0 \%$, our results would justify focusing HCV screening and services on key and vulnerable populations of MSM and PWID.

Clinical awareness of HCV among specific populations of PLWA, including PWID, MSM, transgender individuals, sex workers and prisoners, must be promoted. ${ }^{[3]}$ The association between HIV and $\mathrm{HCV}$ infection, which includes sexual transmission of HCV, should be considered. ${ }^{[12]}$ It is well described that individuals from key populations experience real or perceived stigma from both society at large and the healthcare sector, which results in lower levels of health access and adverse health outcomes. HCV appears to be concentrated among key populations in SA, which provides a further obstacle to addressing the burden of HCV disease. There is an ethical imperative to work towards creating an enabling and non-discriminatory healthcare environment, where individuals from key populations are welcomed and where their specific health concerns, such as HCV screening, can be accommodated. Clinicians may require sensitivity training to enable them to engage with key population risk groups regarding $\mathrm{HCV}$ exposure and infection. Referral pathways for specialist management (and cure) of people with HCV infection or complications, such as liver fibrosis or cirrhosis, are necessary.

PWID need access to syringe and needle exchange and opiate drug-substitution therapy, ${ }^{[3]}$ delivered in enabling and de-stigmatised environments as per the recommendations of the WHO for prevention of HIV and HCV. ${ }^{[5,29]}$

Currently, it appears as if the HCV epidemic is concentrated in specific populations rather than being a generalised epidemic. This knowledge should assist health planners with regard to current and future responses to HCV. Further research is necessary, including better mapping of at-risk populations, as well as population level surveillance. ${ }^{[3]}$

HCV is treatable with new oral DAA drugs, which dramatically improve cure rates and side-effect profiles. ${ }^{[2,3]}$ These drugs should 
allow for easier expansion of treatment access. ${ }^{[3]}$ DAA therapy needs to be made available, accessible and affordable. Policymakers, government and civil groups should advocate for the treatment of HCV. The need to treat HIV and HCV co-infected people has to be emphasised. ${ }^{[3]}$

\section{Study limitations}

The small sample size and convenience sampling method conducted at one specialist clinic site limit generalisability of our results. Financial constraints precluded RT-PCR to confirm active HCV infection or genotyping for all participants.

Accuracy of responses to study questions depends on respondents' memory and recall. Additionally, experiences of stigma and discrimination in the health environment with regard to MSM's sexual behaviours and drug use might have made responses subject to social desirability bias. The extensive experience of ITCMH and Anova Health Institute's Health4Men initiative in working together with MSM and PWID regarding their psychological and physical health should mitigate this bias to some extent.

\section{Recommendations}

Valid diagnostic algorithms for HCV need to be developed, with specific consideration of the disease epidemiology in African populations. ${ }^{[3,9]}$ Standardisation of testing algorithms will allow realistic comparison across studies. Evidence-based normative guidance would also allow clinicians an efficient investigatory path for diagnosing $\mathrm{HCV}$ infection and promote linkage to care.

Acknowledgements. The authors would like to acknowledge the staff of the Anova Health Institute's Ivan Toms Centre for Men's Health for implementation of harm-reduction services, and the men who have attended the service and participated in the research.

Author contributions. All authors contributed equally to this work.

Funding. This project received support and funding from the AIDS Fonds and Mainline, Amsterdam, the Netherlands (grant no. 2011066).

Conflicts of interest. None.

1. Hagan $\mathrm{H}$, Jordan AE, Neurer J, Cleland CM. Incidence of sexually transmitted hepatitis C virus

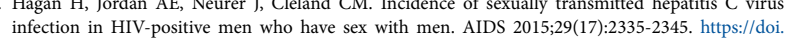
infection in HIV-positive men who

2. Westbrook RH, Dusheiko G. Natural history of hepatitis C. J Hepatol 2014;61(Suppl 1):S58-S68. https://doi.org/10.1016/j.jhep.2014.07.012

3. Suthar AB, Harries AD. A public health approach to hepatitis $\mathrm{C}$ control in low- and middle-income countries. PLoS Med 2015;12(3):e1001795. https://doi.org/10.1371/journal.pmed.1001795

4. Hernandez MD, Sherman KE. HIV/hepatitis C coinfection natural history and disease progression. Curr Opin HIV AIDS 2011;6(6):478-482. https://doi.org/10.1097/COH.0b013e32834bd365
5. World Health Organization. Guidelines for the Screening, Care and Treatment of Persons with Hepatitis C Infection. Geneva: WHO, 2014.

6. Rao VB, Johari N, du Cros P, Messina J, Ford N, Cooke GS. Hepatitis C seroprevalence and HIV 6. Rao VB, Johari N, du Cros P, Messina J, Ford N, Cooke GS. Hepatitis C seroprevalence and HIV
co-infection in sub-Saharan Africa: A systematic review and meta-analysis. Lancet Infect Dis co-infection in sub-Saharan Africa: A systematic review and

7. Mullis CE, Laeyendecker O, Reynolds SJ, et al. High frequency of false-positive hepatitis C virus Mullis CE, Laeyendecker O, Reynolds SJ, et al. High frequency of false-positive hepatitis C virus
enzyme-linked immunosorbent assay in Rakai, Uganda. Clin Infect Dis 2013;57(12):1747-1750. https://doi.org/10.1093/cid/cit602

8. Chasela CS, Wall P, Drobeniuc J, et al. Prevalence of hepatitis C virus infection among human immunodeficiency virus-1-infected pregnant women in Malawi: The BAN study. J Clin Virol 2012;54(4):318 320. https://doi.org/10.1016/j.jcv.2012.05.003

9. Rouet F, Deleplancque L, Mboumba BB, et al. Usefulness of a fourth generation ELISA assay for the reliable identification of $\mathrm{HCV}$ infection in HIV-positive adults from Gabon (central Africa). PloS ONE 2015;10(1):e0116975. https://doi.org/10.1371/journal.pone.0116975

10. Kaplan-Lewis E, Fierer DS. Acute HCV in HIV-infected MSM: Modes of acquisition, liver fibrosis, and treatment. Curr HIV/AIDS Rep 2015;12(3):317-325. https://doi.org/10.1007/s11904-015-0279-3

11. Cassidy MJD, Jankelson D, Becker M, Dunne T, Walzl G, Moosa MR. The prevalence of antibodies to Cassidy MJD, Jankelson D, Becker M, Dunne T, Walz G, Moosa MR. The prevalence of antibodes
hepatitis C virus at two haemodialysis units in South Africa. S Afr Med J 1995;85(10):996-998.

12. Amin J, Kaye M, Skidmore S, Pillay D, Cooper DA, Dore GJ. HIV and hepatitis C coinfection within the
hepatis Amin J, Kaye M, Skidmore S, Pillay D, Cooper DA, Dore GJ. HIV and hepatitis C coinfection within the
CAESAR study. HIV Med 2004;5(2004):174-179. https://doi.org/10.1111/j.1468-1293.2004.00207.x

13. Tohme RA, Holmberg SD. Is sexual contact a major mode of hepatitis C virus transmission? Tohme RA, Holmberg SD. Is sexual contact a major mode of hepalt
Hepatology 2010;52(4):1497-1505. https://doi.org/10.1002/hep.23808

14. Tathiah N, Parboosing R, Singh L, Jinabhai CC, Moodley P. Human immunodeficiency virus and hepatitis B or C co-infection in KwaZulu-Natal: A retrospective analysis of a laboratory database. South Afr J Infect Dis 2014;29(1):19-22.

15. Parboosing R, Paruk I, Lalloo UG. Hepatitis C virus seropositivity in a South African cohort of HIV co-infected, ARV naïve patients is associated with renal insufficiency and increased mortality. J Med Viro 2008;80(9):1530-1536. https://doi.org/10.1002/jmv.21262

16. Platt L, Easterbrook P, Gower E, et al. Prevalence and burden of HCV co-infection in people living with HIV: A global systematic review and meta-analysis. Lancet Infect Dis 2016;16(7):797-808. https://doi. org/10.1016/S1473-3099(15)00485-5

17. Gededzha MP, Mphahlele MJ, Lukhwareni A, Selabe SG. Should routine serological screening for HCV be mandatory in HIV/AIDS patients enrolling for HAART in South Africa? S Afr Med J 2010;100(12):814-815.

18. Gogela N, Sonderup M, Rebe K, Chivese T, Spearman W. The sero-prevalence of hepatitis $\mathrm{C}$ in an HIV Gogela N, Sonderup M, Rebe K, Chivese T, Spearman W. The sero-prevalence of hepatitis C in an HIV
infected population of heterosexual and men who have sex with men (MSM). S Afr Med J 2013;103(8):568infected population of heterosexual and
575. https://doi.org/10.7196/SAMJ.7178

19. Firnhaber C, Reyneke A, Schulze D, et al. The prevalence of hepatitis B co-infection in a South African urban government HIV clinic. S Afr Med J 2008;98(7):541-544.

20. Hoffmann CJ, Dayal D, Cheyip M, et al. Prevalence and associations with hepatitis B and hepatitis C infection among HIV-infected adults in South Africa. Int J STD AIDS 2012;23(10):e10-e13. https:// doi.org/10.1258/ijsa.2009.009340

21. Barth RE, Huijgen Q, Tempelman HA, Mudrikova T, Wensing AMJ, Hoepelman AIM. Presence of occult $\mathrm{HBV}$, but near absence of active $\mathrm{HBV}$ and $\mathrm{HCV}$ infections in people infected with HIV in rural South Africa. J Med Virol 2011;83(6):929-934. https://doi.org/10.1002/jmv.22026

22. Lodenyo H, Schoub B, Ally R, Kairu S, Segal I. Hepatitis B and C virus infections and liver function in AIDS patients at Chris Hani Baragwanath Hospital, Johannesburg. East Afr Med J 2000:77(1):13-15.

23. Mwatela RS, Lwembe RM, Osman $S$, et al. Co-infection burden of hepatitis $C$ virus and Mwatelah RS, Lwembe RM, Osman S, et al. Co-infection burden of hepatitis C virus an human immunodeficiency virus among injecting heroin users a

24. Muasya T, Lore W, Yano K, et al. Prevalence of hepatitis $\mathrm{C}$ virus and its genotypes among a cohort of Muasya T, Lore W, Yano K, et al. Prevalence of hepatitis
drug users in Kenya. East Afr Med J 2008;85(7):318-325.

25. Tun W, Vu L, Adebajo SB, et al. Population-based prevalence of hepatitis B and C virus, HIV, syphilis, gonorrhoea and chlamydia in male injection drug users in Lagos, Nigeria. Int J STD AIDS 2013;24(8):619-625. https://doi.org/10.1177/0956462413477553

26. Leprêtre A, Ba I, Lacombe K, et al. Prevalence and behavioural risks for HIV and HCV infections in a population of drug users of Dakar, Senegal: The ANRS 12243 UDSEN study. J Int AIDS Soc 2015;18:19888. https://doi.org/10.7448/IAS.18.1.19888

27. Bowring AL, Luhmann N, Pont S, et al. An urgent need to scale-up injecting drug harm reduction services in Tanzania: Prevalence of blood-borne viruses among drug users in Temeke District, Dar-esSalaam, 2011. Int J Drug Policy 2013;24(1):78-81. https://doi.org/10.1016/j.drugpo.2012.08.005

28. Fadlalla FA, Mohamoud YA, Mumtaz GR, Abu-Raddad LJ. The epidemiology of hepatitis C virus in the Maghreb region: Systematic review and meta-analyses. PLoS ONE 2015;10(3):e0121873. https:// the Maghreb region: Systematic revilio.1371/journal.pone. 0121873
doi

29. World Health Organization. Consolidated Guidelines on HIV Prevention, Diagnosis, Treatment and Care for Key Populations. Geneva: WHO, 2014. 